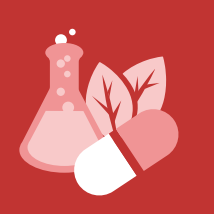

\title{
Scientia Pharmaceutica
}

an Open Access Journal by MDPI

Tracked for
Impact

CITESCORE

5.3

Partner Societies:

I Austrian Pharmaceutical Society (ÖPhG) 11 D $\rightarrow \begin{aligned} & \text { Academic Open Access Publishing } \\ & \text { since } 1996\end{aligned}$ 


\section{Scientia Pharmaceutica}

an Open Access Journal by MDPI

\section{Editor-in-Chief}

Prof. Dr. Helmut Viernstein

Department of Pharmaceutical

Technology and

Biopharmaceutics, Faculty

of Life Sciences, University of

Vienna, Austria

\section{Message from the Editor-in-Chief}

Scientia Pharmaceutica is a unique journal offering insight into the diverse fields of Pharmaceutical Sciences. One advantage of Scientia Pharmaceutica is that it covers a very wide scope, starting from pharmacobotany and pharmacognosy/pharmaceutical biology, through natural products/pharmaceutical/medicinal chemistry, analytics, pharmacology and pharmaceutical technology/drug development, to clinical studies and the practice of pharmacy. The journal publishes high standard papers submitted by researchers of the respective and neighboured disciplines, thus allowing a broad overview, including nutritional sciences, hospital pharmacy, history of pharmacy, etc.

Scientia Pharmaceutica is a worthy journal for everybody interested in the continued progress and latest developments in the Pharmaceutical Sciences.

\section{Author Benefits}

Open Access Unlimited and free access for readers

C No Copyright Constraints Retain copyright of your work and free use of your article

\section{\& Thorough Peer-Review}

ป No Space Constraints, No Extra Space or Color Charges No restriction on the length of the papers, number of figures or colors

$\mathrm{DC}$ Coverage by Leading Indexing Services Scopus, ESCI (Web of Science), Embase, CAPlus / SciFinder, and other databases

( Rapid Publication First decision provided to authors approximately 27.9 days after submission; acceptance to publication is undertaken in 7.2 days (median values for papers published in this journal in the first half of 2022) 


\section{Aims and Scope}

Scientia Pharmaceutica - Official Organ of the Austrian Pharmaceutical Society (Österreichische Pharmazeutische Gesellschaft, ÖPhG) - publishes original research papers, short communications and a limited number of reviews from all fields of pharmaceutical sciences and related disciplines, as well as from pharmaceutical practice.

In particular the following areas are covered:

Medicinal and Pharmaceutical Chemistry: Synthesis, analysis and modelling of biologically active substances and pharmaceuticals

\section{Pharmacognosy and Pharmaceutical Biology:}

Isolation and structure elucidation of natural substances; morphology, systematics, taxonomy of medicinal and poisonous plants; quality of medicines of biological origin

Pharmacology: Pharmacological testing of synthetic and natural products; clinical pharmacy; mechanisms of drug (inter-)actions

Pharmaceutical Technology: Strategies of drug development; controlled drug release; drug targeting Contributions on pharmacy-didactics, pharmaeconomy, nutritional sciences, book reviews, and proposals for pharmacopoeia-monographs

Editorial Office

Sci. Pharm. Editorial Office scipharm@mdpi.com MDPI, St. Alban-Anlage 66 4052 Basel, Switzerland Tel: +41 616837734 www.mdpi.com mdpi.com/journal/scipharm 


\section{CASPA}

The Association of Learned \& Professional

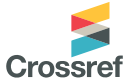

\section{STM}

Society

for Scholarly

Publishing
$|\mathbf{C}| \mathbf{O}|\mathbf{P}| \mathbf{E}$

SPARC *

Europe

\section{DOAJ}

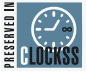

ORCID

\section{Partner Societies}

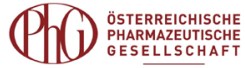

\section{Follow}

f facebook.com/MDPIOpenAccessPublishing

twitter.com/MDPIOpenAccess

in linkedin.com/company/mdpi

(O) instagram.com/mdpiopenaccess

6 weibo.com/mdpicn

is Wechat: MDPI-China

\section{Subscribe}

blog.mdpi.com 